\title{
Mesothelin Positive
}

National Cancer Institute

\section{Source}

National Cancer Institute. Mesothelin Positive. NCI Thesaurus. Code C128841.

Indicates that mesothelin expression has been detected in a sample. 